\title{
Clinical significance of decreased programmed cell death 4 expression in patients with giant cell tumors of the bone
}

\author{
FEI GAO $^{1^{*}}$, WEI ZHANG ${ }^{2 *}$, LINGLING DING $^{3^{*}}$, MIAOQING ZHAO ${ }^{4}$, ZHE MA $^{5}$ and SHANYING HUANG ${ }^{1}$
}

\author{
${ }^{1}$ The Key Laboratory of Cardiovascular Remodeling and Function Research, Chinese Ministry of Education, \\ Chinese National Health Commission and Chinese Academy of Medical Sciences, The State and \\ Shandong Province Joint Key Laboratory of Translational Cardiovascular Medicine, Department of Cardiology, \\ Shandong University Qilu Hospital, Jinan, Shandong 250012; ${ }^{2}$ Department of Orthopedics; ${ }^{3}$ Center for Reproductive \\ Medicine; ${ }^{4}$ Department of Pathology, Shandong Provincial Hospital Affiliated to Shandong University, Jinan, \\ Shandong 250021; ${ }^{5}$ Department of Ultrasound, Shandong University Qilu Hospital, Jinan, Shandong 250012, P.R. China
}

Received January 8, 2018; Accepted June 13, 2018

DOI: $10.3892 / \mathrm{ol} .2018 .9087$

\begin{abstract}
Programmed cell death 4 (PDCD4) has been recognized as a novel tumor suppressor gene, which inhibits the activation and translation of activator protein (AP)-1. Dysregulated expression of PDCD4 is also involved in various human tumors and is linked to tumor progression and development. However, the function and clinical implication of PDCD4 in giant cell tumors of the bone (GCTBs) has not been previously investigated. In the present study, PDCD4 expression was determined in 83 samples of GCTBs at mRNA and protein levels by quantitative reverse transcription-polymerase chain reaction, western blotting and immunohistochemistry. The results demonstrated that PDCD4 mRNA expression was reduced in $63 \%$ of GCTB samples (17/27) and protein expression was decreased in $65 \%$ of samples (54/83), compared with adjacent non-tumor tissues. Furthermore, decreased expression of PDCD4 was significantly associated with certain clinicopathological characteristics, including the Campanacci grade and recurrence. A strong negative correlation was determined between PDCD4 expression and the Ki-67 positive rate in GCTBs $(\mathrm{r}=-0.6392 ; \mathrm{P}<0.001)$. The results of the present study suggest that PDCD4 may serve a role in the malignant
\end{abstract}

Correspondence to: Dr Fei Gao, The Key Laboratory of Cardiovascular Remodeling and Function Research, Chinese Ministry of Education, Chinese National Health Commission and Chinese Academy of Medical Sciences, The State and Shandong Province Joint Key Laboratory of Translational Cardiovascular Medicine, Department of Cardiology, Shandong University Qilu Hospital, 107 Wen Hua Xi Road, Jinan, Shandong 250012, P.R. China

E-mail: gaofeijn@126.com

${ }^{*}$ Contributed equally

Key words: programmed cell death 4, expression, giant cell tumors of the bone, clinical significance progression of human GCTBs and may be an important prediction factor for prognosis.

\section{Introduction}

Giant cell tumor of the bone (GCTB) is generally a benign, but often locally aggressive osteolytic tumor which easily causes severe bone destruction at the meta-epiphyseal region of the long bones and more than half of GCTBs occur around the knee $(1,2)$. With modern surgical techniques, more aggressive curettage may aid in avoiding higher recurrence rates (3). However, it has been reported that $\sim 10-60 \%$ of GCTBs exhibit local postoperative recurrence (4-6), $10 \%$ of GCTBs undergo malignant transformation and up to $5 \%$ of GCTBs exhibit pulmonary metastases (7). GCTBs have diverse histological subtypes (8). Characterized by high proliferative abilities, GCT stromal cells are the major type in GCTBs (9). Although numerous studies have focused on cell proliferation and cell cycle regulation of GCTBs, which serve a key role in the decreased recurrence rates and improved clinical outcomes, there is little evidence of certain regulators or signaling pathways, which could be regarded as predictive markers for recurrence or metastasis. In this regard, it is necessary to investigate the biological and clinical function of certain molecules involved in the development and metastasis of GCTBs, which may be used as novel biomarkers for the diagnosis and prognosis of patients with giant cell tumors.

Programmed cell death 4 (PDCD4) is a novel tumor suppressor and a promising candidate for a targeted molecular therapy for tumors based on regulating different cellular signal transduction pathways. PDCD4 could restrain the growth, malignant transformation and metastasis of tumor cells at mRNA, protein and cellular levels (10). It has been reported that nuclear PDCD4 inhibits the activity of transcription factor activator protein-1 (AP-1) and controls gene transcription in mouse epidermal JB6 cells $(11,12)$. PDCD4 could also suppress cap-dependent translation of mRNAs with highly structured 5'-regions through interaction with the eukaryotic translation initiation factor 4A helicase (13). Furthermore, PDCD4 gene knockout mice developed spontaneous tumors 
of lymphoid origin (14). However, Jansen et al (15) observed a significant reduction in the carcinoma incidence and papilloma-to-carcinoma conversion frequency in PDCD4 transgenic mice compared with wild-type mice.

Recently, numerous studies have identified a decreased expression of PDCD4 in multiple types of human cancer cell lines and primary tumors, including cervical cancer (16), gastric cancer (17), glioma (18), hepatocellular carcinoma (19), gastrointestinal stromal tumors (20) and nasal inverted papilloma (21). Certain studies have demonstrated that PDCD4 served a role in the progression of osteocarcinoma. Nevertheless, the precise regulation of PDCD4 in GCTBs remains largely unknown. In the present study, expression of PDCD4 was decreased in GCTBs compared with adjacent non-tumor tissues. In addition, it was demonstrated that abnormal PDCD4 expression level was associated with clinicopathological features, including the Campanacci grade and recurrence.

\section{Materials and methods}

Clinical specimens. A total of 83 GCTB samples, including 27 frozen and 56 paraffin-embedded tissues, were collected from patients (median age, 40 years old), who underwent surgery at the Department of Orthopedics, Shandong Provincial Hospital Affiliated to Shandong University from September 2015 to March 2017. The specimens were immediately frozen in liquid $\mathrm{N}$ after surgery and stored at $-80^{\circ} \mathrm{C}$. Written informed consent was obtained from all participants. The present study was approved by the ethics guidelines of Chinese Medical Association. The protocol was completely approved by the Shandong Provincial Hospital Institutional Review Board (IRB). None of the patients had received immunotherapy, radiotherapy or chemotherapy prior to surgery. GCTBs were staged using the Campanacci grading system (22).

RNA Extraction and quantitative reverse transcription-PCR (qRT-PCR). Total RNA was extracted from frozen tissues of primary GCTBs using a modified TRIzol one-step extraction method (Invitrogen; Thermo Fisher Scientific, Inc., Waltham, MA, USA) $(23,24)$. First-strand cDNA was synthesized from $3 \mu \mathrm{g}$ total RNA using the Revert Aid First Strand c-DNA Synthesis kit (Promega Corporation, Madison, WI, USA) according to the manufacturer's protocol. The PCR primer pairs specific for PDCD4 were as follows: Forward, 5'-CCA AAGAAAGGTGGTGCA-3' and reverse, 5'-TGAGGTACT TCCAGTTCC-3'. The following thermocycling conditions were used for the PCR: Initial denaturation at $94^{\circ} \mathrm{C}$ for $2 \mathrm{~min}$; 35 cycles of denaturation at $95^{\circ} \mathrm{C}$ for $90 \mathrm{sec}$, annealing at $66^{\circ} \mathrm{C}$ for $90 \mathrm{sec}$ and extension at $72^{\circ} \mathrm{C}$ for $90 \mathrm{sec}$. Human $\beta$-actin was used as an internal control. The primers for $\beta$-actin were forward, 5'-CATGTACGTTGCTATCCAGGC-3', and reverse, 5'-CTCCTTAATGTCACGCACGAT-3'. Each sample was obtained from three independent experiments and used for analysis of relative normalized mRNA expression.

Western blot analysis. Protein lysates were separated by SDS-PAGE. The concentration of protein was determined using BCA Protein Assay (Beyotime Institute of Biotechnology, Haimen, China). Then, the protein were transferred onto polyvinylidene difluoride membranes and were blocked with 5\% skim milk in TBST containing $0.1 \%$ Tween-20 for $1 \mathrm{~h}$. The filters were incubated with primary antibodies against PDCD4 (1:5,000, cat. no. 9535; Cell Signaling Technology, Inc., Danvers, MA, USA) and $\beta$-actin (1:1,000, sc-47778; Santa Cruz Biotechnology, Inc., Dallas, TX, USA), followed by secondary antibody (1:2,000, Anti-rabbit IgG, HRP-linked Antibody cat. no. 7074; Cell Signaling Technology, Inc.) conjugated with peroxidase for $1 \mathrm{~h}$ at room temperature. The immune complexes were visualized by the enhanced chemiluminescence reagent (SuperSignal West Pico Chemiluminescent Substrate; Pierce; Thermo Fisher Scientific, Inc.). Western blot analysis was performed at least 3 times for each sample.

Immunohistochemistry. Tissue sections (4-6 $\mu \mathrm{m})$ from frozen and paraffin blocks were dewaxed in xylene and rehydrated in alcohol. Antigen retrieval of sections was achieved by microwaving in citric saline and treatment with $3 \%$ hydrogen peroxide. Immunohistochemical staining using PDCD4 (1:100, PAB10308; Abnova, Taipei, Taiwan) and anti-Ki-67 antibodies (1:500, M724029, Dako; Agilent Technologies, Inc., Santa Clara, CA, USA) was performed to delineate PDCD4 expression and cell proliferation in tumor samples. Sections were also stained with hematoxylin. The intensity and percentage area of PDCD4 staining was categorized into five grades: Score $0(-)$, score $1(+)$, score $2(++)$, score $3(+++)$, score $4(++++)$ and score $5(+++++)$. Scores of 4 or 5 indicated relatively high expression of PDCD4, while scores of 0-3 indicated relatively low expression. All staining experiments were performed in duplicate. Slides were evaluated by two independent pathologists.

Statistical analysis. All statistical analyses were performed using SPSS v.22.0 statistical software package (IBM Corp., Armonk, NY, USA). Two-way analysis of variance with Student-Newman-Keuls post hoc test or Student's t-test was performed to determine statistical significance. The significance of differences between groups was estimated by $\chi^{2}$ and Pearson's coefficient tests. The associations were analyzed by Spearman's correlation and multivariate regression analyses. All statistical analyses were two-sided and values are presented as the mean \pm standard error of the mean. $\mathrm{P}<0.05$ was considered to indicate a statistically significant difference. Statistical significance was evaluated with data from at least three independent experiments.

\section{Results}

Decreased expression of PDCD4 is observed in GCTBs at the mRNA level. The present study first quantified the expression of PDCD4 mRNA in primary GCTBs by qRT-PCR. The mRNA level of PDCD4 was markedly decreased or absent in 63\% (17/27) of the frozen GCTB samples compared with adjacent non-tumorous tissues (Fig. 1A). The results demonstrated that there was a significantly differential expression of PDCD4 between primary GCTBs and non-tumorous tissues at the mRNA level (Fig. 1B).

PDCD4 protein expression is decreased in GCTBs. To further determine the PDCD4 expression, western blot analysis was 

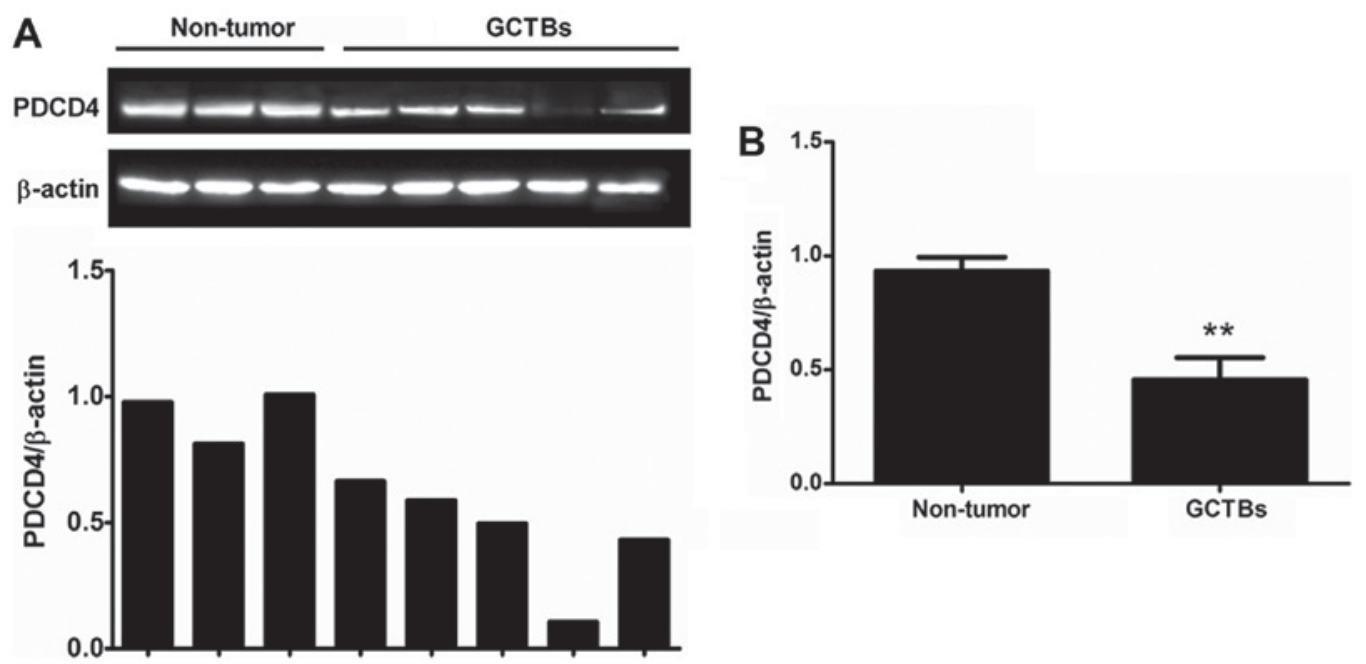

Figure 1. Relative mRNA PDCD4 expression in GCTB. (A) The expression levels of PDCD4 mRNA in adjacent non-tumor tissues and in primary GCTB were detected by reverse transcription-polymerase chain reaction. Data were normalized to $\beta$-actin. (B) Relative expression levels of PDCD4 in GCTB tissues $(\mathrm{n}=27)$ compared with the corresponding non-tumor tissues $(\mathrm{n}=13) .{ }^{* *} \mathrm{P}<0.01$ vs. non-tumor tissue. PDCD4, programmed cell death 4; GCTB, giant cell tumor of the bone.
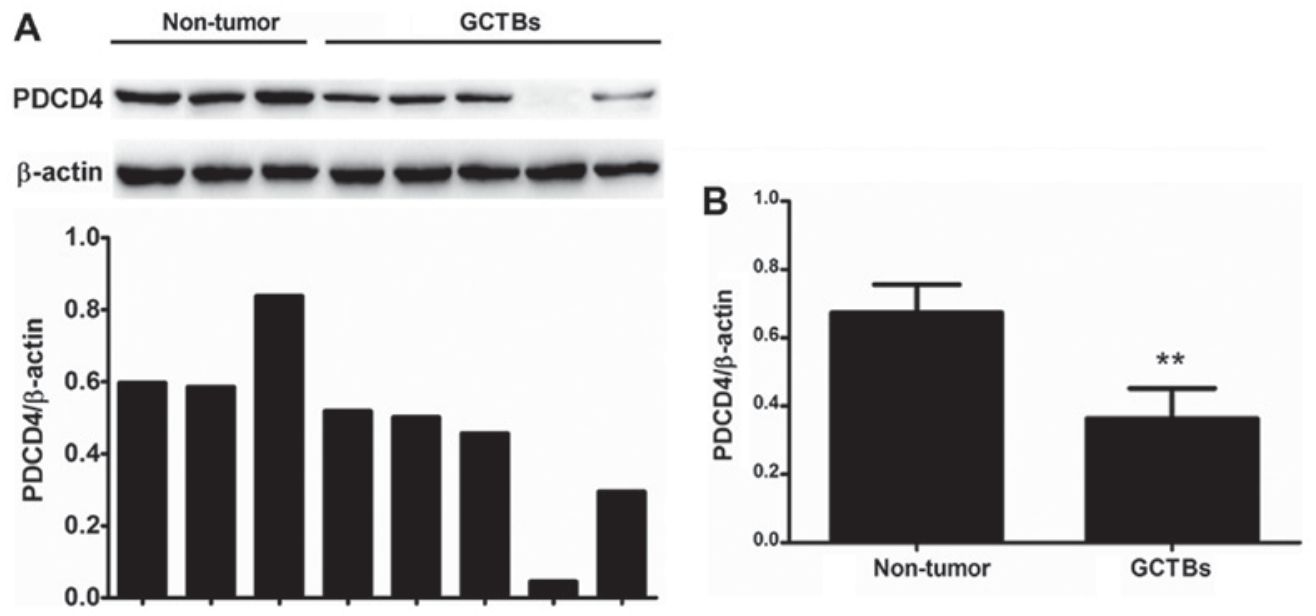

Figure 2. PDCD4 protein expression in GCTB. (A) Western blot analysis revealed the expression of PDCD4 in adjacent non-tumor tissues and primary GCTB $\beta$-actin protein was used as the internal control. (B) Normalized PDCD4 protein expression in GCTB tissues $(\mathrm{n}=27)$ compared with corresponding non-tumor tissues (n=13). ${ }^{* *} \mathrm{P}<0.01$ vs. non-tumor tissue. PDCD4, programmed cell death 4; GCTB, giant cell tumor of bone.
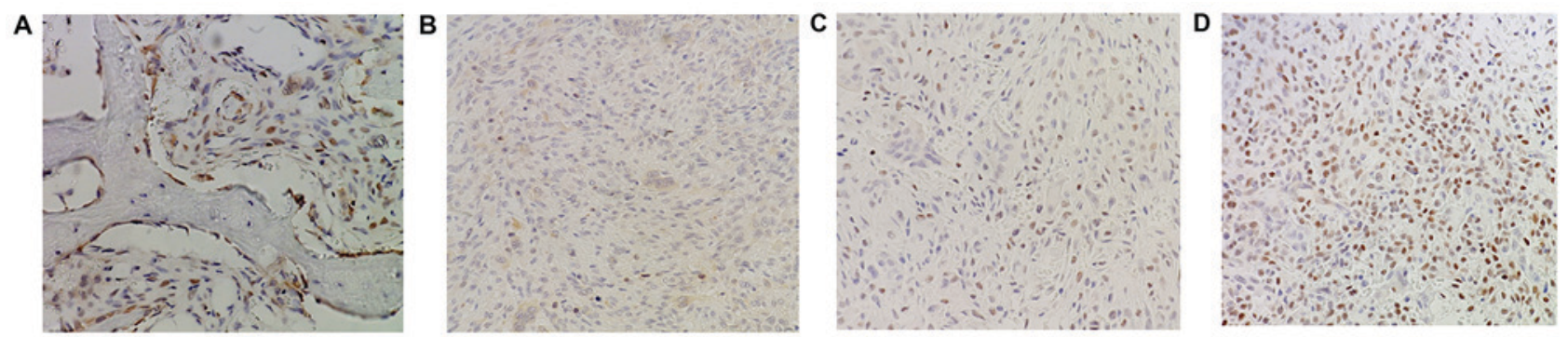

Figure 3. PDCD4 protein expression in GCTB as detected by immunohistochemistry. (A) The tumor sections were subjected to IHC staining with an antibody against PDCD4. There was a strong expression of PDCD4 detected in adjacent non-tumor tissues. The tumor sections were subjected to IHC staining with an antibody against PDCD4 in primary GCTB to identify (B) score 0, (C) score 1 and (D) score 4 (magnification, x400). PDCD4, programmed cell death 4; GCTB, giant cell tumor of the bone; IHC, immunohistochemical.

performed to identify the protein level of PDCD4. The results demonstrated that the protein level of PDCD4 was significantly decreased in $63 \%$ of frozen GCTB samples (17/27) compared with adjacent non-tumorous tissues and this observation was in accordance with experimental results at the mRNA level (Fig. 2). Furthermore, the protein level of PDCD4 was also 
Table I. Association between PDCD4 expression and clinicopathological characteristics in patients with giant cell tumor of the bone.

\begin{tabular}{lcc}
\hline Parameters & PDCD4 low expression & PDCD4 high expression \\
\hline Total no. of patients & 54 & 29 \\
Sex & & \\
Male & 23 & 7 \\
Female & 31 & 22
\end{tabular}

Age (years)

$\geq 40$

$<40$

Tumor location

Distal femur

Proximal humerus

Distal radius

Other position

Tumor size

$\begin{array}{ll}\geq 5 \mathrm{~cm} & 19 \\ <5 \mathrm{~cm} & 35\end{array}$

$19-16$

Campanacci grade

$35-13$

I 12

II 31

III 11

$12-15$

10

Recurrence

$11-4$

Yes $\quad 21$

No

$21 \quad 5$

$33 \quad 24$

Ki-67 labeling index (\%)

$13.28 \pm 5.06$

${ }^{\mathrm{a}} \mathrm{P}<0.05 ;{ }^{\text {b }}<0.001$. PDCD4, Programmed cell death 4 .

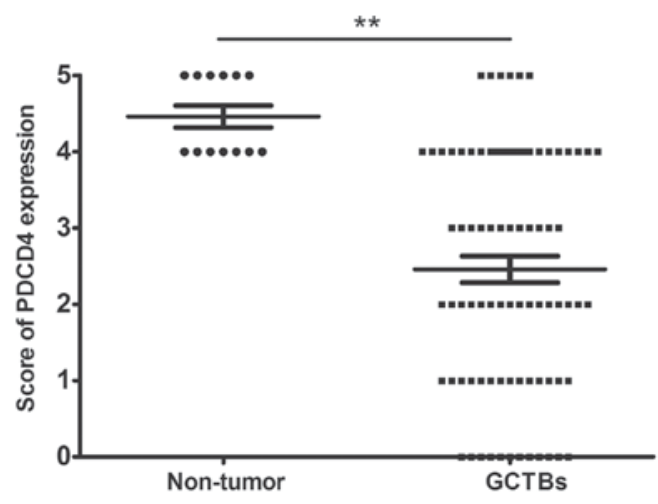

Figure 4. Expression of PDCD4 is downregulated in GCTB as demonstrated by the distribution analysis of PDCD4 staining in GCTB and adjacent non-tumor tissues. IHC analysis revealed PDCD4 expression in 83 GCTBs and 13 adjacent non-cancerous tissues. The overall level of PDCD4 expression was significantly lower in GCTB compared with the adjacent non-tumor tissues according to the results of IHC. ${ }^{* *} \mathrm{P}<0.01$. The dots indicate non-tumor tissue cases and the squares indicate GCTB cases. PDCD4, programmed cell death 4; GCTB, giant cell tumor of the bone; IHC, immunohistochemistry.

detected in GCTB samples by immunohistochemistry using frozen and paraffin-embedded tissues. It was demonstrated that normal tissues adjacent to tumors exhibited strong PDCD4 staining (Fig. 3A), while diminished or no staining of PDCD4 was observed in the tumor tissues (Fig. 3B-D). Altogether, the expression of PDCD4 at the protein level was decreased in $65 \%(54 / 83)$ of tumor specimens, with a marked differential expression of PDCD4 between GCTBs and normal tissues at the protein level (Fig. 4).

PDCD4 expression is associated with clinicopathological characteristics in primary GCTBs. The clinical role of PDCD4 in primary GCTBs was subsequently analyzed and the association between the PDCD4 expression and clinicopathological characteristics of GCTBs was studied. No significant correlation was determined between PDCD4 expression and patients' sex, age, tumor location and tumor size. However, PDCD4 expression was significantly associated with the Campanacci grade and tumor recurrence $(\mathrm{P}<0.05$; Table I), which indicated that decreased PDCD4 expression may promote the progression of GCTBs.

PDCD4 inhibits malignant proliferation of GCTBs. It was previously demonstrated that $\mathrm{Ki}-67$ protein is closely associated with the malignant proliferation of GCTBs (25). Therefore, 

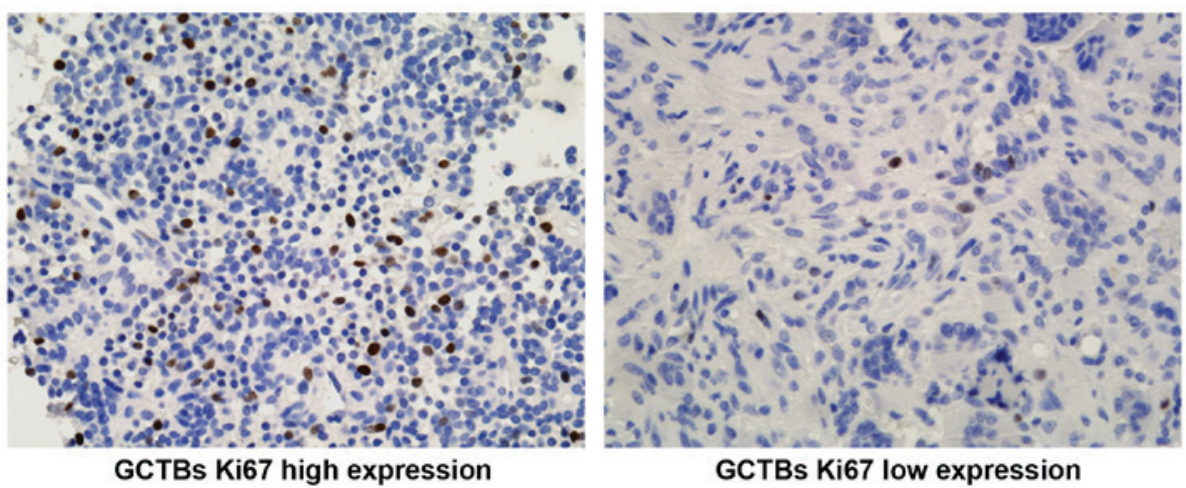

Figure 5. Immunohistochemistry analysis of Ki-67 in GCTB. GCTB samples exhibited different Ki-67 protein expression (magnification, x400). GCTB, giant cell tumor of bone.

A

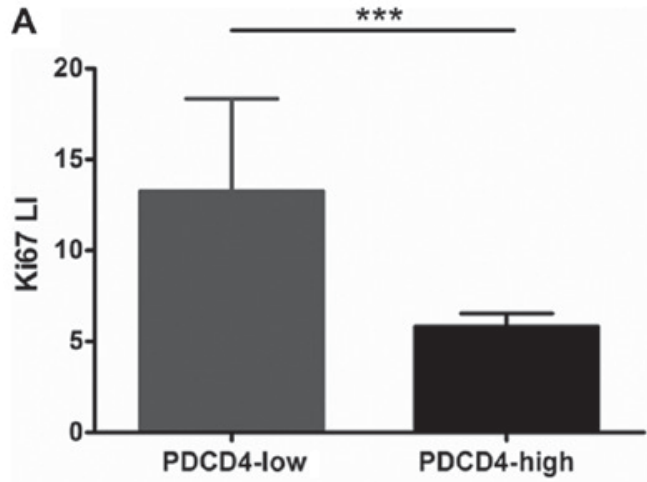

B

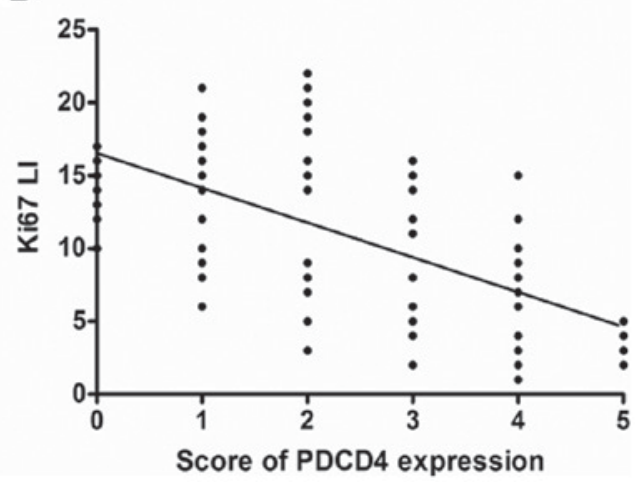

Figure 6. PDCD4 inhibits cell proliferation in CGTB. (A) Ki-67 LI assay was conducted to determine the viability of GCTB in the PDCD4 low expression group (54 samples) and the PDCD4 high expression group (29 samples). ${ }^{* * *} \mathrm{P}<0.001$. (B) PDCD4 expression exhibited a strong negative correlation with Ki-67 LI $(r=-0.6392 ; \mathrm{P}<0.001)$. The mean value was used to determine the low/high cut off value. Ki-67 LI, Ki-67 labeling index; PDCD4, programmed cell death 4; GCTB, giant cell tumor of the bone.

the present study further examined the Ki-67 expression at the protein level in GCTBs (Fig. 5) and confirmed the association between the Ki-67 LI (Ki-67 labeling index) and the expression of PDCD4. The Ki-67 LI of GCTBs with low expression of PDCD4 was markedly increased compared with GCTBs exhibiting high expression of PDCD4 ( $\mathrm{P}<0.001$; Fig. 6A). The results demonstrated that PDCD4 may have a negative association with the Ki-67 LI ( $r=-0.6392 ; \mathrm{P}<0.001$; Fig. 6B). All data suggested that PDCD4 may have an important effect on inhibition of the malignant proliferation of GCTBs.

\section{Discussion}

Multiple studies using animal models and human tumors have confirmed that PDCD4 is a novel tumor suppressor gene that can inhibit tumor progression and neoplastic transformation. Decreased or absent PDCD4 expression is associated with the development and prognosis of various types of cancer. The present study analyzed PDCD4 expression in GCTBs samples and adjacent non-tumorous tissues and revealed that PDCD4 expression at the mRNA level was reduced in $63 \%$ of frozen samples. The protein level was diminished in more than half of all samples compared with the control, the adjacent non-tumor tissues with high expression of PDCD4 at the mRNA and protein level. In addition, there was an association between the PDCD4 expression and the Campanacci grade or recurrence. Furthermore, PDCD4 exhibited a negative association with the Ki-67 LI, which indicated the increased proliferation of tumor cells. PDCD4 expression may serve a role in tumor malignant progression and may aid the prognosis prediction of human GCTBs.

Surgery is a standard treatment for localized primary GCTBs. Although en bloc excision of a primary tumor can reduce the recurrence rate to $<20 \%$, intralesional curettage has been reported to result in high recurrence rates of up to $40-50 \%$ in certain series (26). The evaluation of expression levels of prognostic marker proteins at the time of diagnosis may be taken into consideration for the classification of GCTBs into categories characterized by a different risk of relapse (27). Therefore, it is particularly important to identify an increased number of novel target molecules for early diagnosis and prediction of clinical behavior for decreasing recurrence and improving the survival of patients with GCTBs.

Previous studies have identified PDCD4 as a novel tumor suppressor gene. Recently, numerous studies of various tumors have demonstrated that PDCD4 is a target for anticancer therapies and may be a potential diagnostic and prognostic marker $(28,29)$. PDCD4 can inhibit the malignant growth of tumor cells and induce an effect on more important cancer-associated genes at different transcriptional and/or 
translational levels (30). However, it was not previously known that there may be an association between the PDCD4 expression and certain clinical, and pathological features in human primary GCTBs tissues, including tumor progression and prognosis.

In the present study, decreased PDCD4 expression at mRNA and protein levels was determined in primary GCTBs. It was previously reported that the expression of PDCD4 could be regulated in various ways at different transcriptional and translational levels (10). Certain studies have suggested that epigenetic mechanisms served a key role in the regulation of expression of PDCD4. We confirmed that PDCD4 5'-CpG island methylation was associated with reduced PDCD4 expression at the mRNA level in human glioma cell lines and tissues. Furthermore, PDCD4 expression could be restored with the inhibition of methylation in glioma cells (31). Therefore, the molecular mechanisms responsible for decreased PDCD4 expression in GCTBs remain to be further elucidated.

The present study demonstrated that abnormal PDCD4 expression was markedly associated with certain clinicopathological features of GCTBs, including the Campanacci grade and tumor recurrence. It has been previously demonstrated that PDCD4 protein expression was associated with clinical and pathological characteristics of diverse types of tumors (10). Our previous study indicated that enhanced PDCD4 expression could improve the prognosis of patients with high-grade glioma (31). Other studies have demonstrated that the expression of PDCD4 protein was associated with a high grade of lung adenocarcinoma. In the present study, lower PDCD4 expression appeared in high Campanacci grade GCTB. PDCD4 negatively regulated $\mathrm{Ki}-67$ expression and inhibited GCTB proliferation. These results suggested that PDCD4 may be an indicator of malignant progression. Based on the correlation between PDCD4 and tumor recurrence, it was concluded that PDCD4 may be a key prognostic molecule in the development of GCTB. Positive and effective therapeutic strategies to upregulate PDCD4 expression may shed light on the treatment of GCTBs (32). PDCD4 was initially identified as a new cell-apoptosis related gene. It may exhibit a marked inhibitory effect on GCTSCs, the primary neoplastic cells of GCTB, but this hypothesis requires further investigation in the future.

In conclusion, the present study suggested that PDCD4 expression may serve an essential role in the malignant progression and proliferation of GCTBs, and may contribute to an improvement in the prognosis of GCTBs. However, the precise molecular mechanism by which PDCD4 expression affects the malignant development of GCTBs requires further investigation.

\section{Acknowledgements}

The authors would like to thank Dr Meng Zhang and Dr Rong Wang for their technical support and Dr Xiao Wang for their helpful comments associated with the present study (all Shandong University Qilu Hospital, Jinan, China).

\section{Funding}

The present study was supported by the National Natural Science Foundation of China (grant nos. 81470403 and 81701404), the Key
Research and Development Plan of Shandong Province (grant nos. 2016GGE27013-2016GSF201091 and 2016GSF201141) and the China Postdoctoral Science Foundation (grant no. 2017M610431).

\section{Availability of data and materials}

The datasets used and/or analyzed during the current study are available from the corresponding author on reasonable request.

\section{Authors' contributions}

FG designed research. WZ and LD performed cases collection and molecular biology assays. Immunohistochemistry analysis was performed by MZ, SH and ZM. FG wrote the manuscript, and the final version was read and approved by all authors.

\section{Ethics approval and consent to participate}

Written informed consent was obtained from all participants prior to their inclusion within the study. The present study was conducted in accordance with the Ethics guidelines of the Chinese Medical Association and the study protocol was approved by the Shandong Provincial Hospital Institutional Review Board.

\section{Patient consent for publication}

Not applicable.

\section{Competing interests}

The authors declare that they have no competing interests.

\section{References}

1. Turcotte RE: Giant cell tumor of bone. Orthop Clin North Am 37: 35-51, 2006

2. Xu M, Song ZG, Xu CX, Rong GH, Fan KX, Chen JY, Zhang W, Jia JP, Han G, Wang W, et al: IL-17A stimulates the progression of giant cell tumors of bone. Clin Cancer Res 19: 4697-4705, 2013.

3. Müller DA, Beltrami G, Scoccianti G, Campanacci DA, Franchi A and Capanna R: Risks and benefits of combining denosumab and surgery in giant cell tumor of bone-a case series. World J Surg Oncol 14: 281, 2016

4. Karpik M: Giant cell tumor (tumor gigantocellularis, osteoclastoma)-epidemiology, diagnosis, treatment. Ortop Traumatol Rehabil 12: 207-215, 2010 (In English, Polish).

5. Muramatsu K, Ihara K and Taguchi T: Treatment of giant cell tumor of long bones: Clinical outcome and reconstructive strategy for lower and upper limbs. Orthopedics 32: 491, 2009.

6. Balke M, Schremper L, Gebert C, Ahrens H, Streitbuerger A, Koehler G, Hardes J and Gosheger G: Giant cell tumor of bone: Treatment and outcome of 214 cases. J Cancer Res Clin Oncol 134: 969-978, 2008.

7. Dominkus M, Ruggieri P, Bertoni F, Briccoli A, Picci P, Rocca M and Mercuri M: Histologically verified lung metastases in benign giant cell tumours-14 eases from a single institution. Int Orthop 30: 499-504, 2006.

8. Van der Heijden L, Dijkstra PDS, Blay JY and Gelderblom H: Giant cell tumour of bone in the denosumab era. Eur J Cancer 77: 75-83, 2017.

9. Yamamoto H, Iwasaki T, Yamada Y, Matsumoto Y, Otsuka H, Yoshimoto M, Kohashi K, Taguchi K, Yokoyama R, Nakashima Y and Oda Y: Diagnostic utility of histone H3.3 G34W, G34R, and G34V mutant-specific antibodies for giant cell tumors of bone. Hum Pathol 73: 41-50, 2018. 
10. Lankat-Buttgereit B and Göke R: The tumour suppressor Pdcd4 Recent advances in the elucidation of function and regulation. Biol Cell 101: 309-317, 2009.

11. Yasuda M, Nishizawa T, Ohigashi H, Tanaka T, Hou DX, Colburn NH and Murakami A: Linoleic acid metabolite suppresses skin inflammation and tumor promotion in mice: Possible roles of programmed cell death 4 induction. Carcinogenesis 30: 1209-1216, 2009.

12. Hsu TC, Young MR, Cmarik J and Colburn NH: Activator protein 1 (AP-1)- and nuclear factor kappaB (NF-kappaB)-dependent transcriptional events in carcinogenesis. Free Radic Biol Med 28: 1338-1348, 2000.

13. Loh PG, Yang HS, Walsh MA, Wang Q, Wang X, Cheng Z, Liu D and Song H: Structural basis for translational inhibition by the tumour suppressor Pdcd4. EMBO J 28: 274-285, 2009.

14. Hilliard A, Hilliard B, Zheng SJ, Sun H, Miwa T, Song W, Göke R and Chen YH: Translational regulation of autoimmune inflammation and lymphoma genesis by programmed cell death 4. J Immunol 177: 8095-8102, 2006.

15. Jansen AP, Camalier CE and Colburn NH: Epidermal expression of the translation inhibitor programmed cell death 4 suppresses tumorigenesis. Cancer Res 65: 6034-6041, 2005.

16. Zhang Z, Wang J, Li J, Wang X and Song W: MicroRNA-150 promotes cell proliferation, migration, and invasion of cervical cancer through targeting PDCD4. Biomed Pharmacother 97: 511-517, 2018.

17. Hu X, Wang Y, Liang H, Fan Q, Zhu R, Cui J, Zhang W, Zen K, Zhang CY, Hou D, et al: miR-23a/b promote tumor growth and suppress apoptosis by targeting PDCD4 in gastric cancer. Cell Death Dis 8: e3059, 2017

18. Gao F, Zhang P, Zhou C, Li J, Wang Q, Zhu F, Ma C, Sun W and Zhang L: Frequent loss of PDCD4 expression in human glioma: Possible role in the tumorigenesis of glioma. Oncol Rep 17: 123-128, 2007.

19. Huang $H$, Wang $X$, Wang $C$, Zhuo L, Luo $S$ and Han S: The miR-93 promotes proliferation by directly targeting PDCD4 in hepatocellular carcinoma. Neoplasma 64: 770-777, 2017.

20. Ding L, Zhang X, Zhao M, Qu Z, Huang S, Dong M and Gao F: An essential role of PDCD 4 in progression and malignant proliferation of gastrointestinal stromal tumors. Med Oncol 29: $1758-1764,2012$.

21. Wang Y, Ding L, Zhang X, Zhao M, Qu Z, Huang S, Zhang Y, Li Y and Gao F: Clinical significance of programmed cell death 4 expression in malignant progression of human nasal inverted papillomas. Med Oncol 29: 2505-2011, 2012.

22. Campanacci M, Baldini N, Boriani S and Sudanese A: Giant-cell tumor of bone. J Bone Joint Surg Am 69: 106-114, 1987.
23. Chadderton T, Wilson C, Bewick M and Glück S: Evaluation of three rapid RNA extraction reagents: Relevance for use in RT-PCR's and measurement of low level gene expression in clinical samples. Cell Mol Biol (Noisy-le-grand) 43: 1227-1234, 1997.

24. Culley DE, Kovacik WP Jr, Brockman FJ and Zhang W: Optimization of RNA isolation from the archaebacterium Methanosarcina barkeri and validation for oligonucleotide microarray analysis. J Microbiol Methods 67: 36-43, 2006.

25. Antal I, Sápi Z and Szendröi M: The prognostic significance of DNA cytophotometry and proliferation index $(\mathrm{Ki}-67)$ in giant cell tumors of bone. Int Orthop 23: 315-319, 1999.

26. Raskin KA, Schwab JH, Mankin HJ, Springfield DS and Hornicek FJ: Giant cell tumor of bone. J Am Acad Orthop Surg 21: 118-126, 2013.

27. Gamberi G, Serra M, Ragazzini P, Magagnoli G, Pazzaglia L, Ponticelli F, Ferrari C, Zanasi M, Bertoni F, Picci P and Benassi MS: Identification of markers of possible prognostic value in 57 giant cell tumors of bone. Oncol Rep 10: 351-356, 2003.

28. Pennelli G, Galuppini F, Barollo S, Cavedon E, Bertazza L, Fassan M, Guzzardo V, Pelizzo MR, Rugge M and Mian C: The PDCD4/miR-21 pathway in medullary thyroid carcinoma. Hum Pathol 46: 50-57, 2015

29. Fassan M, Pizzi M, Battaglia G, Giacomelli L, Parente P, Bocus P, Ancona E and Rugge M: Programmed cell death 4 (PDCD4) expression during multistep Barrett's carcinogenesis. J Clin Pathol 63: 692-696, 2010.

30. Wang WQ, Zhang H, Wang HB, Sun YG, Peng ZH, Zhou G, Yang SM, Wang RQ and Fang DC: Programmed cell death 4 (PDCD4) enhances the sensitivity of gastric cancer cells to TRAIL-induced apoptosis by inhibiting the PI3K/Akt signaling pathway. Mol Diagn Ther 14: 155-161, 2010.

31. Gao F, Wang X, Zhu F, Wang Q, Zhang X, Guo C, Zhou C, Ma C, Sun W, Zhang Y, et al: PDCD4 gene silencing in gliomas is associated with $5^{\prime} \mathrm{CpG}$ island methylation and unfavourable prognosis. J Cell Mol Med 13: 4257-4267, 2009.

32. Briest F, Berndt A, Clement J, Junker K, Eggeling Fv, Grimm S and Friedrich $\mathrm{K}$ : Tumor-stroma interactions in tumorigenesis: Lessons from stem cell biology. Front Biosci (Elite Ed) 4: 1871-1887, 2012.

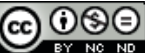

This work is licensed under a Creative Commons Attribution-NonCommercial-NoDerivatives 4.0 International (CC BY-NC-ND 4.0) License. 